\title{
Erratum
}

\section{Erratum to: The Jacobi Matrix for Functions in Noncommutative Algebras}

\author{
Reiner Lauterbach and Gerhard Opfer
}

In the original publication of the article, the following table is missing at the end of the paper:

Table 9.3 Solutions $x=\left(x_{1}, x_{2}, x_{3}, x_{4}\right)$ of $\exp (x)=\mathbf{j} x^{-1}$ with respect to algebras $\mathcal{A}$ No 3 and No 7 .

\begin{tabular}{c|r|r|r|r} 
No & $x_{1}$ & $x_{2}$ & $x_{3}$ & $x_{4}$ \\
\hline 3 & -0.926022412499 & 2.856210427246 & -0.607890907294 & 1.518974725816 \\
& -1.798095524696 & 1.606723012705 & 0.264182204902 & -5.981908165767 \\
\hline 7 & -1.812521021861 & 0.722872107973 & 4.798875608830 & -7.565238212111 \\
& -0.357474946570 & 0.732173967307 & -1.094974940121 & 1.671387663153 \\
& -1.461960307143 & -0.372311393265 & 1.609736192846 & 4.376098796120
\end{tabular}

The norms of the five solutions are between $1.495 \cdot 10^{-15}$ and $4.614 \cdot 10^{-12}$.

Reiner Lauterbach and Gerhard Opfer

University of Hamburg,

Faculty for Mathematics, Informatics, and Natural Sciences [MIN],

Bundestraße 55, 20146 Hamburg, Germany

e-mail: reiner.lauterbach@uni-hamburg.de

gerhard.opfer@uni-hamburg.de 